\title{
Study on the risk evaluation model of catering 020 food quality and safety
}

\author{
Dong-Ping TANG1, SADDAM FUAD HUSSEIN AL QADAMI1, Xue-Min WANG1*, Cui-Ying CAI1 \\ ${ }^{1}$ Departments of Business Administration, University of South China University of Technology, 510640, Guangzhou, Guangdong
}

\begin{abstract}
The purpose of this paper is to analyze the risk points that may lead to food safety in the operation and development of catering $\mathrm{O} 2 \mathrm{O}$ supply chain. Based on the operational mode of catering $\mathrm{O} 2 \mathrm{O}$ supply chain, the system risk factors were identified by theoretical and literature analysis. Also, the expert Delphi method was used to put forward a comparatively perfect food quality and safety risk assessment system in catering $\mathrm{O} 2 \mathrm{O}$ industry, and an evaluation model was constructed based on the fuzzy comprehensive evaluation method of analytic hierarchy process (AHP) to provide a reference for the development of food safety management of the catering $\mathrm{O} 2 \mathrm{O}$ industry.
\end{abstract}

\section{Introduction}

In recent years, new catering $\mathrm{O} 2 \mathrm{O}$ industries such as "Internet + catering" have emerged. However, beneath the surface of a thriving catering industry are many food safety concerns. In order to solve the problem of $\mathrm{O} 2 \mathrm{O}$ food safety effectively, we must pay attention to the research of food quality and safety management in catering O2O supply chain. At present, the research on food quality and its management is still very few [2]. As a new product in the Internet era, the regulation and research of catering $\mathrm{O} 2 \mathrm{O}$ mode is still in its infancy, especially in the food quality risk assessment in catering $\mathrm{O} 2 \mathrm{O}$ supply chain. Therefore, it is of great theoretical and practical significance to to build a new food safety risk manage- ment system of catering $\mathrm{O} 2 \mathrm{O}$. Also, it guides relevant departments more practical and timely to carry out food safety risk management.

\section{Operational Mode and Risk Analysis of Catering 020 Supply Chain}

\subsection{Operational mode of catering $\mathrm{O} 20$ sup- ply chain}

Catering $\mathrm{O} 2 \mathrm{O}$ supply chain is mainly based on the $\mathrm{O} 2 \mathrm{O}$ platform for information collection and transmission. It's operational flow is shown in figure 1.

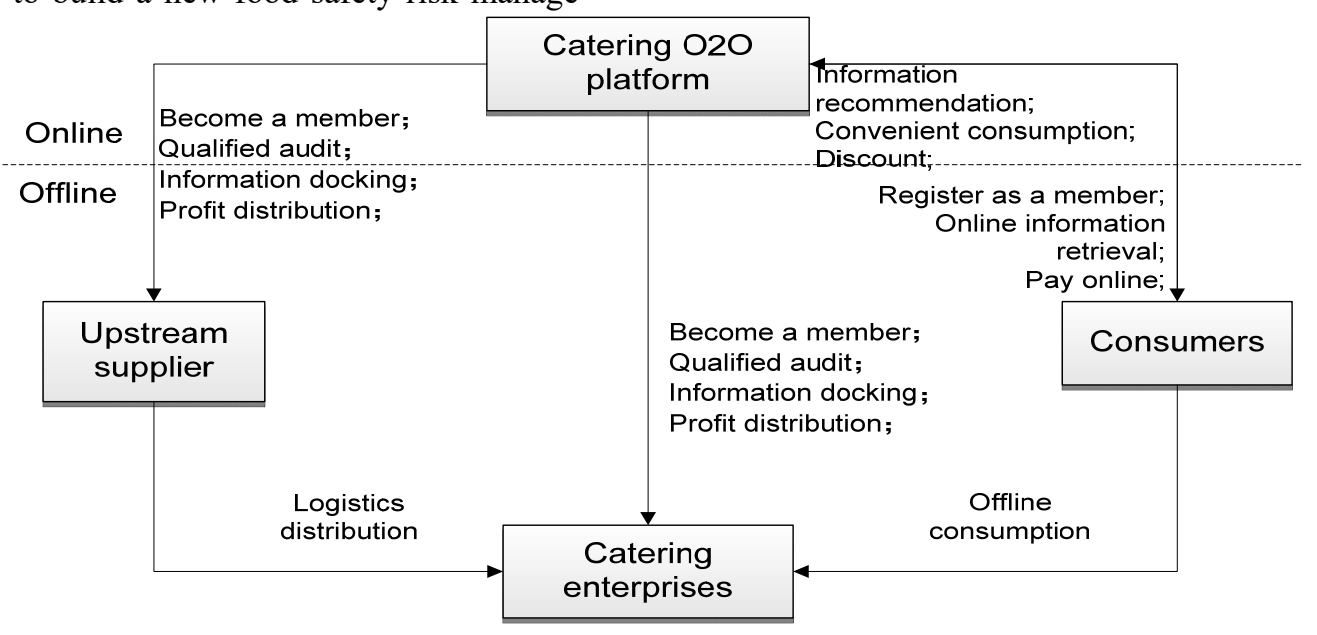

Figure 1. The operational flow of the catering O2O supply chain.

\subsection{Identification and Analysis of Food Safe- ty Risk of Catering $\mathrm{O} 20$}

According to catering $\mathrm{O} 2 \mathrm{O}$ supply chain operation process, food quality risk factors were identified and divided into three parts: online subsystem risk, offline subsystem risk and system external risk.

Email of all the authors: Dong-Ping TANG: 653473738@qq.com; SADDAM FUAD HUSSEIN AL QADAMI: saddam_foad 3000@hotmail.com; Xue-MinWANG:614388749@qq.com; Cui-Ying CAI: 2287996516@qq.com

* Corresponding Author:Xue-Min WANG; email:614388749@qq. com; phone: 18023452243. 


\subsubsection{Online subsystem risk}

Online subsystem risk refers to the food quality risk caused by online part of the catering $\mathrm{O} 2 \mathrm{O}$ supply chain which can be divided into the following three links according to its operation process: platform entry, consumption decision and evaluation feedback.

\subsubsection{Offline subsystem risk}

Offline subsystem risk refers to the food quality risk caused by offline part of the catering $\mathrm{O} 2 \mathrm{O}$ supply chain. This part of the risk can be similar to the risk of the traditional catering supply chain system, which can be divided into the following three major parts: food production, circulation and catering consumption.

\subsubsection{System external risk}

The system external risk comes from the change of market environment, legal policy and technology develop- ment of external supply chain system. It is mainly divided into macroscopic environment and technological environment.

\section{Establishment of risk evaluation mod- el of catering $\mathrm{O} 2 \mathrm{O}$ food quality based on supply chain}

\subsection{Establishment of food safety risk sys- tem}

This paper uses theoretical and literature analysis methods and selects the food quality safety risk factors in existing literature of related domain as the reference source from the perspective of the supply chain. On this basis, Delphi method is used by designing the questionnaire of food quality risk factors in catering $\mathrm{O} 2 \mathrm{O}$ supply chain to form a food quality risk assessment index model, which is shown in figure 2 below.

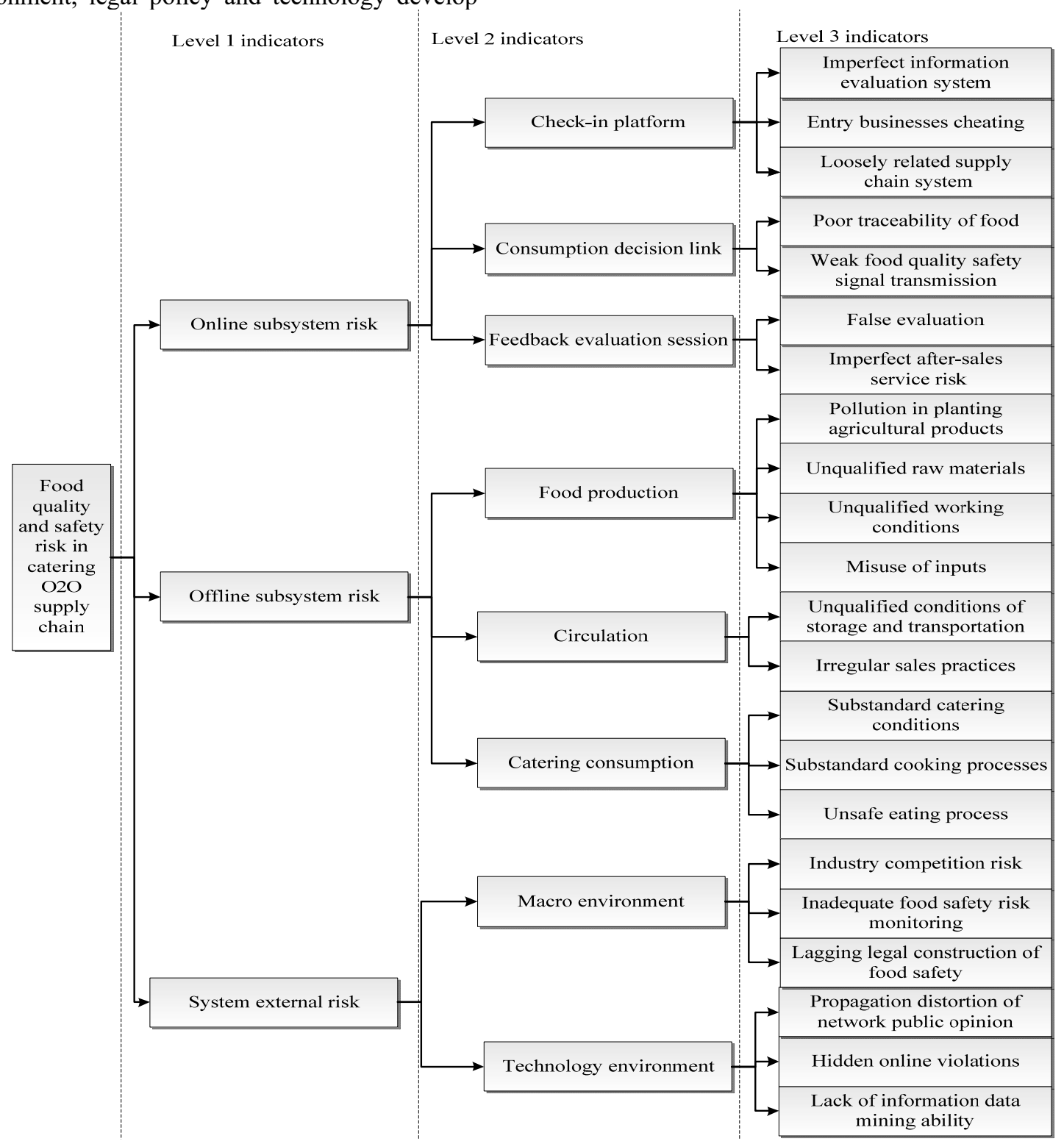

Figure 2. Food quality risk hierarchy model in catering $\mathrm{O} 2 \mathrm{O}$ supply chain. 


\subsection{Establishment of food safety risk as- sessment model}

This paper uses analytic hierarchy process (AHP) and fuzzy comprehensive evaluation method to construct the catering $\mathrm{O} 2 \mathrm{O}$ food quality risk evaluation model. Firstly, the weight of risk factors in the index system is calculated by AHP. Then, risk assessment level set and index membership matrix are established. Finally, the fuzzy comprehensive evaluation is carried out according to the weight calculated by AHP and the evaluation matrix is obtained by the expert scoring method.

\subsubsection{The construction of hierarchical structure model of risk evaluation}

Risk factors are divided into hierarchical structures to construct the risk hierarchy model, determine the index factors at all levels, and form the risk evaluation index set.

$$
\begin{aligned}
& \mathrm{A}=(\mathrm{A} 1, \mathrm{~A} 2, \mathrm{~A} 3)=\{(\mathrm{A} 111, \mathrm{~A} 112, \mathrm{~A} 113), \\
& (\mathrm{A} 121, \mathrm{~A} 122), \cdots, \quad(\mathrm{A} 321, \mathrm{~A} 322, \mathrm{~A} 323)\}
\end{aligned}
$$

\subsubsection{Calculation of judgment matrix and rela- tive weight}

In the analytic hierarchy process (AHP) of this paper, 9level bipolar scale is used to depict the relative importance of the factors in each level through the natural numbers 1 to 9 . Suppose $\overline{\mathrm{C}}$ is the judgment matrix of $A_{i j}$, and $b_{m n}$ is the importance ratio of the tertiary indicator $\mathrm{A}_{\mathrm{ijm}}$ and $\mathrm{A}_{\mathrm{ijn}}$ to secondary indicator $\mathrm{A}_{\mathrm{ij}}$. Then:

$$
\overline{\mathrm{C}}=\left(\mathrm{b}_{\mathrm{mn}}\right)_{\mathrm{kk}}=\left[\begin{array}{cccc}
\mathrm{b}_{11} & \mathrm{~b}_{12} & \ldots & \mathrm{b}_{1 \mathrm{k}} \\
\mathrm{b}_{21} & \mathrm{~b}_{22} & \ldots & \mathrm{b}_{2 \mathrm{k}} \\
& & & \\
\mathrm{b}_{\mathrm{k} 1} & \mathrm{~b}_{\mathrm{k} 2} & \ldots & \mathrm{b}_{\mathrm{kk}}
\end{array}\right] \text {; }
$$

According to the synthesized weight calculation results of each scheme layer, the weight of each hierarchy factor can be obtained: $\mathrm{W}=(\mathrm{w} 1, \mathrm{w} 2, \mathrm{w} 3)$; $\mathrm{Wi}=$ (wi1,wi2,.., wij); Wij= (wij1,wij2,.., wijk) .This article selects Yaahp (Yet Another AHP) V10.3 software to carry on the model construction, the judgment matrix data entry as well as the weight computation.

\subsubsection{Fuzzy comprehensive evaluation}

Determine the level of risk evaluation, establish index membership matrix and construct the risk evaluation vectors. The maximum value of evaluation vectors is the final evaluation result.

\section{Application of food quality risk as- sessment model}

\subsection{Sample data source}

In this survey, a total of 100 questionnaires were sent out, 93 of which were recovered and 88 of which were valid. The effective recovery rate of the questionnaire was $88 \%$.

\subsection{Risk assessment of food quality and safety}

Calculate the weight of risk factors in the way of AHP. Figure out the membership degree of all levels of food quality risk indicators in catering $\mathrm{O} 2 \mathrm{O}$ supply chain in the way of grade-specific gravity method. According to the establishment of food safety risk assessment model, one of the index weight and membership degree results as shown in Table 1:

\begin{tabular}{c|c|c|c|c|c|c|c|c}
\multicolumn{7}{c}{ Table 1. Level 1 indicator weight and membership degree table. } \\
\hline $\begin{array}{c}\text { Level 1 indica- } \\
\text { tors } \\
\text { (Ai) }\end{array}$ & $\begin{array}{c}\text { Weight } \\
\text { (Wi) }\end{array}$ & $\begin{array}{c}\text { Minimum } \\
\text { risk }\end{array}$ & $\begin{array}{c}\text { Lower } \\
\text { Risk }\end{array}$ & $\begin{array}{c}\text { Low } \\
\text { Risk }\end{array}$ & $\begin{array}{c}\text { Medium } \\
\text { Risk }\end{array}$ & $\begin{array}{c}\text { High } \\
\text { Risk }\end{array}$ & $\begin{array}{c}\text { Higher } \\
\text { Risk }\end{array}$ & $\begin{array}{c}\text { Maxi- } \\
\text { mum Risk }\end{array}$ \\
\hline $\begin{array}{c}\text { Online subsystem } \\
\text { risk (A1) }\end{array}$ & 0.2793 & 0.03 & 0.06 & 0.27 & 0.31 & 0.23 & 0.10 & 0.01 \\
\hline $\begin{array}{c}\text { Offline subsys- } \\
\text { tem risk (A2) }\end{array}$ & 0.5724 & 0.00 & 0.04 & 0.31 & 0.23 & 0.22 & 0.21 & 0.05 \\
\hline $\begin{array}{c}\text { System external } \\
\text { risk (A3) }\end{array}$ & 0.1483 & 0.00 & 0.07 & 0.17 & 0.18 & 0.30 & 0.19 & 0.08 \\
\hline
\end{tabular}

The evaluation vector of food quality risk in catering O2O supply chain can be obtained according to the weight matrix and membership degree matrix of the first level index: $\mathrm{P}=\mathrm{Wi} \bullet \mathrm{Ri}=(0.0084,0.0500,0.2449$, $0.2781,0.2347,0.1763,0.0433)$

In the evaluation vector $\mathrm{P}$, the maximum membership degree is 0.2781 , and the corresponding risk fuzzy comprehensive evaluation score is 4.46 , which corresponds to "average risk" in the risk grade assessment.

\subsection{Risk assessment results analysis}

The comprehensive evaluation of food safety risk in catering $\mathrm{O} 2 \mathrm{O}$ supply chain at this stage is "average risk". This indicates that in the current market environment and industry background, catering $\mathrm{O} 2 \mathrm{O}$ food safety risk is in a relatively mild state and the overall food safety risk level is acceptable, but there is still room for improvement. 


\section{Conclusions}

By analyzing the evaluation results, this paper puts forward the following four suggestions: improve the catering safety risk identification and warning mechanism in the $\mathrm{O} 2 \mathrm{O}$ mode, improve awareness of risk management of Internet food safety, improve the level of Internet catering information technology, and strengthen supervision of food safety in Internet catering.

\section{Acknowledgements}

Fund project: Project supported by National Natural Science Foundation of China "Research on behavior decision and mechanism of supply chain cooperation under collaborative innovation environment" (71473087), SRP project supported by South China University of Technology (2018B16043).

\section{References}

1. I Research. (2018) 2018 China smart catering industry research report [EB/OL]. http://report.iresearch.cn /report /201803/3185.shtml.

2. Qing WANG. (2016) Food safety management and construction in the era of "Internet + " $[\mathrm{J}]$. In: Economic management. Abstract version. 2016(8):00262-00262.

3. Xing-Ying WANG. (2016) Study on the civil liability of third party platform for online food ordering [D]. In: Chongqing university.

4. Si-Wu YANG. (2017) Study on food safety supervision of online ordering [D]. In: Zhengzhou university.

5. Yi-Fan HU. Li-Xia LI. Xi-Tong LI. (2016) Supervision of online food safety from the perspective of governance theory. $[\mathrm{J}]$. In: Journal of Shandong institute of administration. 2016(4):75-79.

6. Ji-Ning WANG. Lei WANG. Ting-Qiang CHEN. (2016) The evolutionary game of "Internet +" behavior in food safety management [J]. In: Technology management research. 36(21):211-218.

7. Wei SONG. (2016) Research on food quality safety risk identification and control from the perspective of supply chain [D]. In: Dalian university of technology.

8. Hong-Xia ZHANG. (2014) Research on quality safety risk control of food supply chain led by core enterprises [D]. In: China agricultural university.

9. Ji-Ning WANG. Miao CHEN. (2016) Research on food supply chain safety supervision based on AHP [J]. In: Food research and development. 37(5):162166.

10. Xiao-Yan XU. Tao CHEN. Yun-Dong MU. (2014) Food safety model based on AHP [J]. In: Journal of Pingdingshan college. 29(2):26-29.

11. Juan ZHENG. Min ZUO. Ling-Li CHEN. (2014)
Study and implementation of food safety risk assessment and early warning system [J]. In: Computer knowledge and skills. 2014(33):7902-7907.

12. Qiang CAI. Jun-Jun WANG. Hai-sheng LI. (2014) Study on food safety evaluation model construction based on neural network [J]. In: Journal of food science and technology. 32(1):69-76.

13. Meng-Yao QIAO. (2013) Study on risk assessment of food supply chain [D]. In: Capital university of economics and trade.

14. Guo-Ji CEN.(2013) Risk assessment and response of fresh produce supply chain [D]. In: Guangxi university.

15. Xun-Ping LEI. Guang-Hua QIU. Chun-Xiao DU. (2014) Food safety evaluation and warning based on supply chain and set on variable weight model [J]. In: Technology management research. v.34, No.316(18):41-47.

16. Chun-Yu ZAHNG. (2017) Study on the implementation strategy and evaluation of catering delivery $\mathrm{O} 2 \mathrm{O}$ logistics distribution [D]. In: North China electric power university (Beijing).

17. Wen KANG. (2016) Research on service quality of $\mathrm{O} 2 \mathrm{O}$ fruit stores in universities based on AHP-fuzzy comprehensive evaluation model [J]. In: Business story. 2016(4). 